\title{
Hubungan antara Pola Menstruasi dengan Kejadian Anemia pada Mahasiswi Prodi Sarjana Kebidanan Unissula Semarang
}

\author{
Suhariyati $^{1}$, Alfiah Rahmawati ${ }^{2}$,Friska Realita ${ }^{3}$ \\ ${ }^{1-3}$ Program Studi Sarjana dan Profesi Bidan Fakultas Kedokteran Unissula Semarang \\ Email: yattiy8@gmail.com
}

Submitted :20/03/2020

Accepted: 04/04/2020

Published: 7/09/2020

\begin{abstract}
Abstrack
Anemia is a health problem for people around the world, especially in developing countries. Teenagers have a high risk of anemia, especially iron anemia. That happens because adolescence requires higher nutrients including iron for growth and development. Young women have a higher risk than young men, this is because young women experience menstruation every month (menstruation). The purpose of this study was to determine the relationship between menstrual patterns and the incidence of anemia in young women in Unissula Midwifery Study Program in Semarang. Method: This study used an analytical survey method with a cross sectional study design. The study was conducted in May with a sample of 39 female students of the second semester of unissula midwifery study program. The sampling technique used is total sampling. Menstrual pattern data were obtained through a structured questionnaire, and hemoglobin levels were obtained by examination using the Family DR tool. Data collection includes coding, editing and tabulating, then the data are analyzed with Chi square. The results showed the relationship of menstrual patterns with the incidence of anemia in young women in Unissula Semarang Midwifery Study Program, it was found that the p value <0.05 (0,000). Conclusion: It can be concluded that there is a significant relationship between menstrual patterns and the incidence of anemia in adolescents in Unissula Midwifery Bachelor Study in Semarang. Adolescents are expected to increase knowledge about anemia and can change adolescent eating behavior for the better.
\end{abstract}

Keywords: anemia incidence, menstrual patterns, young women.

\begin{abstract}
Abstrak
Anemia merupakan masalah kesehatan orang diseluruh dunia, terutama dinegara berkembang . Remaja memiliki risiko tinggi terhadap kejadian anemia terutama anemia zat besi. Hal itu terjadi karena masa remaja memerlukan zat gizi yang lebih tinggi termasuk zat besi untuk pertumbuhan dan perkembangannya. Remaja putri memiliki risiko yang lebih tinggi dibandingkan remaja putra, hal ini dikarenakan remaja putri setiap bulannya mengalami haid (menstruasi). Tujuan penelitian untuk mengetahui hubungan antara pola menstruasi dengan kejadian anemia pada Remaja Putri di Prodi Sarjana Kebidanan Unissula Semarang. Penelitian ini menggunakan metode survey analitik dengan rancangan penelitian cross sectional. Penelitian dilaksanakan pada bulan mei dengan sampel sebanyak 39 Mahasiswi prodi sarjana kebidanan unissula semester 2. Teknik Sampling yang digunakan adalah Total sampling. Data pola menstruasi diperoleh melalui kuesioner terstruktur, dan kadar hemoglobin diperoleh dengan pemeriksaan menggunakan alat Family DR. Pengumpulan data meliputi coding, editing dan tabulating, kemudian data dianalisis dengan Chi square. Hasil penelitian menunjukan hubungan pola menstruasi dengan kejadian anemia pada Remaja Putri di Prodi Sarjana Kebidanan Unissula Semarang diketahui bahwa nilai $p$ value $<0,05$ $(0,000)$. Dapat disimpulkan bahwa ada hubungan yang signifikan antara pola menstruasi dengan kejadian anemia Pada Remaja di Prodi Sarjana Kebidanan Unissula Semarang. Remaja diharapkan dapat meningkatkan pengetahuan tentang anemia dan dapat merubah perilaku makan remaja menjadi lebih baik.
\end{abstract}

Kata kunci: kejadian anemia, pola menstruasi, remaja putri. 


\section{PENDAHULUAN}

Pola menstruasi adalah serangkaian proses menstruasi yang terdiri dari siklus menstruasi, lama perdarahan menstruasi dan banyak kehilangan darah menstruasi. Siklus menstruasi merupakan waktu sejak hari pertama menstruasi sampai datangnya menstruasi periode berikutnya. Sedangkan siklus menstruasi pada wanita normalnya berkisar antara 21-35 hari dan hanya 10$15 \%$ yang memiliki siklus menstruasi 28 hari dengan lama menstruasi 3-5 hari, ada yang 7-8 hari. Setiap hari ganti pembalut 25 kali. Panjangnya siklus menstruasi ini dipengaruhi oleh usia, berat badan, aktivitas fisik, tingkat stres, genetik dan gizi (Wiknjosastro, 2002)

Siklus menstruasi yang tidak normal merupakan salah satu faktor pemicu terjadinya anemia. Kehilangan banyak darah saat menstruasi dapat menyebabkan anemia. Banyaknya darah yang dikeluarkan oleh tubuh berpengaruh pada kejadian anemia, karena wanita tidak mempunyai simpanan zat besi yang terlalu banyak dan absorpsi zat besi yang rendah kedalam tubuh sehingga, tidak dapat menggantikan zat besi yang hilang selama menstruasi (Prastika, 2011). Kehilangan darah secara kronis juga dapat mengakibatkan terjadinya anemia. Pada wanita, terjadi kehilangan darah secara alami setiap bulannya. Jika darah yang keluar selama menstruasi sangat banyak maka akan terjadi anemia defisiensi besi. Lama menstruasi yang berlangsung lebih dari 8 hari dan siklus menstruasi yang pendek, yaitu kurang dari 28 hari memungkinkan untuk kehilangan besi dalam jumlah yang lebih banyak (Kirana, 2011)

Remaja memiliki risiko tinggi terhadap kejadian anemia terutama anemia zat besi. Hal itu terjadi karena masa remaja memerlukan zat gizi yang lebih tinggi termasuk zat besi untuk pertumbuhan dan perkembangannya. Remaja putri memiliki risiko yang lebih tinggi dibandingkan remaja putra, hal ini dikarenakan remaja putri setiap bulannya mengalami haid (menstruasi). Selain itu remaja putri cenderung sangat memperhatikan bentuk badannya sehingga akan membatasi asupan makan dan banyak pantangan terhadap makanan seperti melakukan diet vegetarian (Almatsier 2011)

Remaja putri merupakan salah satu kelompok yang rawan menderita anemia, hal ini disebabkan remaja putri dalam usia reproduksi setiap harinya memerlukan zat besi tiga kali lebih banyak dibandingkan dengan remaja putra karena remaja putri mengalami menstruasi setiap bulannya. World Health Organisation (WHO) Regional Office South East Asia Region Organisation (SEARO) menyatakan bahwa $25-40 \%$ remaja putri menjadi penderita anemia defisiensi zat besi tingkat ringan sampai berat di Asia Tenggara (Tim Poltekkes Depkes Jakarta I, 2010).

Anemia merupakan masalah kesehatan orang diseluruh dunia, terutama dinegara berkembang. Diperkirakan 9 persen prevalensi anemia di negara-negara maju, sedangkan 43 persen prevalensi anemia masih terjadi dinegara berkembang. Kelompok yang paling berisiko terjadinya anemia adalah anak-anak dan wanita usia subur (WUS), dengan perkiraan 47 persen prevelensi anemia pada balita, 42 persen pada wanita hamil, dan pada usia 15-49 tahun wanita yang tidak hamil usia sebesar 30 persen. World Health Organization (WHO) menargetkan penurunan prevalensi anemia pada WUS sebesar 50 persen pada tahun 2025.

Di Indonesia, prevalensi anemia masih cukup tinggi. Depkes (2010) dalam Poltekkes Depkes Jakarta I (2010) menunjukkan bahwa penderita anemia pada remaja putri berjumlah 26,50\%. Berdasarkan Riset Kesehatan Dasar pada tahun 2010 yaitu sementara lebih dari $10 \%$ anak usia sekolah di Indonesia mengalami anemia (Riskesdas, 2010). Menurut 
Riskesdas 2013 prevalensi anemia gizi besi pada remaja sebesar $22,7 \%$. Di Indonesia prevalensi $26 \%$ untuk anak perempuan dan $11 \%$ untuk anak laki laki. Departemen Kesehatan dalam Kirana (2011) menunjukkan penderita anemia pada remaja putri berjumlah 26,50\% dan wanita (WUS) $26,9 \%$. Hal ini mengindikasikan anemia masih menjadi masalah kesehatan di Indonesia. Di Jawa Tengah remaja dengan anemia cukup tinggi mencapai angka 43,2\% (Profil Kesehatan Prov. Jateng, 2010).

Dampak dari anemia itu sendiri dinilai sebagai masalah yang sangat serius terhadap kesehatan masyarakat. Masalah kesehatan masyarakat yang berkaitan dengan kejadian anemia pada remaja adalah pucat, lemah, letih, pusing, selain itu dapat menurunkan kemampuan, prestasi dan konsentrasi belajar, menghambat pertumbuhan fisik dan perkembangan kecerdasan otak. Dampak anamia pada wanita dapat menurunkan daya tahan tubuh sehingga penderita anemia mudah terkena penyakit infeksi dan menurunkan produktivitas kerja. Remaja putri yang mengalami anemia akan menyebabkan gangguan kebugaran akibat kurangnya oksigen ke sel otot dan sel otak, membuat remaja menjadi tidak dalam kondisi fit saat berolah raga sehingga dapat menurunkan kinerja remaja (Widyastuti, 2009). Dalam studi pendahuluan yang dilakukan pada 6 mahasiswi program sarjana kebidanan Unissula Semarang tahun 2019, terdapat 3 diantaranya mempunyai pola menstruasi yang tidak normal yaitu siklus yang memanjang, 1 diantaranya mengalami menstrusi dalam jumlah banyak, dan 2 diantaranya mempunyai pola menstruasi normal. Dan ketika dilakukan wawancara terhadap 6 mahasiswi yang saat ditanyakan 4 diantaranya mengatakan sering mengantuk, terkadang lemas dan lesu. Dari 6 mahasiswi tersebut yang diperiksa kadar Haemoglobinnya terdapat 4 yang mengalami kadar hemoglobin kurang dari $12 \mathrm{gr} / \mathrm{dl}$.

Tujuan penelitian ini untuk mengetahui hubungan antara pola menstruasi dengan kejadian anemia pada remaja di prodi sarjana dan profesi bidan unissula semarang.

\section{METODE PENELITIAN}

Penelitian ini menggunakan metode survey analitik yang digunakan untuk mengetahui hubungan hubungan pola menstruasi dengan kejadian anemia pada remaja putri di Prodi Sarjana dan Profesi Bidan Unissula Semarang. Adapun pendekatan yang digunakan yaitu cross sectional. Populasi dalam penelitian ini adalah Seluruh Mahasiswi semester dua di Prodi Sarjana dan Profesi Bidan Unissula Semarang. yang berjumlah 39. Sampel dalam penelitian ini Seluruh Mahasiswi semester dua di Prodi Sarjana dan Profesi Bidan Unissula Semarang. yang berjumlah 39, dengan menggunakan teknik total sampling. Alat yang digunakan untuk mengumpulkan data dalam penelitian ini diambil dari data primer dan data sekunder. Analisa yang digunakan yaitu analisa Univariat dengan distribusi frekuensi, dan Analisa Bivariat dengan menggunakan uji chi square.

\section{HASIL DAN PEMBAHASAN}

a. Analisis Univariat

Distribusi Frekuensi Pola Menstruasi Mahasiswi Prodi Sarjana Kebidanan Unissula. Hasil analisis univariat pola menstruasi Mahasiswi Prodi Sarjana Kebidanan Unissula Semarang dapat dilihat pada tabel 1 berikut:

Tabel 1. Distribusi Frekuensi Pola Menstruasi Mahasiswi Prodi Sarjana Kebidanan Unissula Semarang

\begin{tabular}{lc}
\hline Pola menstruasi & Frekuensi \\
\hline Normal & $15(38,5 \%)$ \\
Tidak normal & $24(61,5 \%)$ \\
\hline Total & $39(100 \%)$ \\
\hline Sumber: Olahan data primer &
\end{tabular}


Berdasarkan tabel 1 mayoritas Mahasiswi Prodi Kebidanan Unissula mengalami pola menstruasi yang tidak normal, yaitu sebanyak $61,5 \%$ dan $38,5 \%$ sisanya mengalami pola menstruasi normal.

Distribusi frekuensi anemia Mahasiswi Prodi Sarjana Kebidanan Unissula Semarang. Hasil analisis univariat anemia Mahasiswi Prodi Sarjana Kebidanan Unissula Semarang dapat dilihat pada tabel 2 berikut:

Tabel 2. Distribusi Frekuensi Kejadian Anemia Pada Mahasiswi Prodi Sarjana Kebidanan Unissula

\begin{tabular}{lc}
\hline Kadar hemoglobin & Frekuensi \\
\hline Anemia & $28(71,8 \%)$ \\
Tidak anemia & $11(28,2 \%)$ \\
Total & $39(100 \%)$ \\
\hline
\end{tabular}

Sumber: olahan data primer

Berdasarkan tabel 2 Mayoritas mahasiswi mengalami anemia sebanyak
$71,8 \%$ dan sisanya $28,2 \%$ tidak mengalami anemia.

b. Analisis bivariate

Hasil analisis hubungan pola menstruasi dengan kejadian anemia pada Mahasiswi Prodi Sarjana Kebidanan Unissula Semarang dapat dilihat pada tabel 3. Berdasarkan tabel 3 Menunjukkan bahwa mayoritas Mahasiswi yang mempunyai pola menstruasi normal tidak mengalami anemia $(60 \%)$ dan mengalami anemia $40 \%$. Sebaliknya Mahasiswi yang memiliki pola menstruasi tidak normal mayoritas mengalami kejadian anemia $(91 \%)$ dan tidak mengalmi anemia 8,3\%. Ditinjau dari uji statistic menggunakan analisis chi square menunjukkan nilai $\mathrm{p}=0,000<$ nilai $\mathrm{a}=0,005$. Ini berarti terdapat hubungan antara pola menstruasi dengan kejadian anemia pada Mahasiswi Prodi Sarjana Kebidanan Unissula Semarang.

Tabel 3. Hubungan Pola Menstruasi dengan Kejadian Anemia pada Mahasiswi Prodi Sarjana Kebidanan Unissula.

\begin{tabular}{|c|c|c|c|c|c|c|c|}
\hline \multirow{3}{*}{ Pola menstruasi } & \multicolumn{4}{|c|}{ Kejadian anemia } & \multirow{2}{*}{\multicolumn{2}{|c|}{ Total }} & \multirow{3}{*}{$\mathrm{P}$ value } \\
\hline & \multicolumn{2}{|c|}{ Anemia } & \multicolumn{2}{|c|}{ Tidak anemia } & & & \\
\hline & $\mathrm{N}$ & $\%$ & $\mathrm{~N}$ & $\%$ & $\mathrm{~N}$ & $\%$ & \\
\hline Normal & 6 & $40 \%$ & 9 & $60 \%$ & 15 & $100 \%$ & \multirow{2}{*}{0,000} \\
\hline Tidak Normal & 22 & $91,7 \%$ & 2 & $8,3 \%$ & 24 & $100 \%$ & \\
\hline Total & 28 & $71,8 \%$ & 11 & $28,2 \%$ & 39 & $100 \%$ & \\
\hline
\end{tabular}

Sumber: Olahan data Chi Square

\section{Pembahasan}

\section{Univariat}

Pola menstruasi Mahasiswi Prodi Sarjana Kebidanan Unissula Semarang

Pada hasil analisis dari 39 Mahasiswi terdapat $24(61,5 \%)$ mengalami pola menstruasi yang tidak normal sedangkan sisanya yaitu 15 mahasiswi $(38,5 \%)$ mempunyai pola menstruasi yang normal.

Menurut Wiknjosastro (2009) faktor yang mempengaruhi pola menstruasi yaitu Fungsi hormonal terganggu, Kelaianan sistemik, Cemas, Kelenjar gondok, Hormon prolaktin berlebih, Kelainan fisik (alat reproduksi). Cakir $\mathrm{M}$ et al (2007) di dalam penelitiannya menemukan $31,2 \%$ remaja di
Turki mengalami ketidak teraturan pola menstruasi. Perbedaan panjangnya pola menstruasi antar wanita biasanya disebabkan karena tidak seimbangnya hormon estrogen, progesteron, LH dan FSH karena suatu penyakit, status gizi maupun stress.

Menurut Pribakti (2012) jika siklusnya tidak lancar seperti lama menstruasi yang panjang atau terlalu cepat, hal ini mungkin disebabkan oleh gangguan pada rahim atau gangguan pada indung telurnya. Namun bila keduanya baik-baik saja, kemungkinan karena terjadi gangguan pada hormon bisa juga karena pengaruh gizi. Asupan zat gizi dan status gizi 
mempengaruhi siklus menstruasi, hal ini berhubungan dengan perubahan kadar hormon steroid yang merupakan faktor dalam proses pengaturan siklus menstruasi. Status gizi adalah suatu ukuran mengenai kondisi tubuh seseorang yang dapat dilihat dari makanan yang dikonsumsi dan penggunaan zat-zat gizi di dalam tubuh (Almatsier, 2010). Penelitian Sugma (2015) menunjukkan stresor seperti meninggalkan keluarga, masuk kuliah, bergabung dengan militer, atau memulai kerja baru berhubungan dengan tidak datangnya menstruasi, meningkatkan panjang siklus menstruasi atau jadi menunda periode setiap bulannya. Adanya perbedaan latar belakang sosiodemografi, tingkat aktivitas dan tingkat kemampuan adaptasi diduga juga menyebabkan timbulnya keluhan stress. a. Anemia pada Mahasiswi Prodi Sarjana Kebidanan Unissula Semarang

Pada penelitian ini mayoritas Mahasiswi mengalami anemia yaitu dari 39 Mahasiswi terdapat $28(71,8 \%)$ mengalami anemia sedangkan sisanya yaitu 11 Mahasiswi (28,2\%) tidak mengalami anemia. Menurut Sakti dkk (2003) Remaja putri juga merupakan salah satu kelompok yang berisiko menderita anemia. Remaja putri mempunyai risiko tinggi untuk anemia karena pada usia ini terjadi peningkatan kebutuhan zat besi akibat pertumbuhan, adanya menstruasi, sering membatasi konsumsi makan, serta pola konsumsinya sering menyalahi kaidah-kaidah ilmu gizi.

Dalam Kirana (2011) Remaja putri memiliki risiko sepuluh kali lebih besar untuk menderita anemia dibandingkan dengan remaja putra. Hal ini dikarenakan remaja putri mengalami menstruasi setiap bulannya dan sedang dalam masa pertumbuhan sehingga membutuhkan asupan zat besi yang lebih banyak. Penjelasan di atas sejalan dengan pendapat Briawan (2014) yang menyebutkan bahwa menstruasi yang dialami oleh remaja putri setiap bulannya merupakan salah satu penyebab dari anemia. Keluarnya darah dari tubuh remaja pada saat menstruasi mengakibatkan hemoglobin yang terkandung dalam sel darah merah juga ikut terbuang, sehingga cadangan zat besi dalam tubuh juga akan berkurang dan itu akan menyebabkan terjadinya anemia. (Dito, 2007).

Menurut Arisman (2006) menyatakan penyebab atau faktor-faktor yang mempengaruhi terjadinya anemia diantaranya adalah kebutuhan zat besi yang meningkat, rendahnya asupan zat besi. Selain itu faktor pendidikan, ekonomi, dan status sosial pada masyarakat merupakan penyebab dasar terjadinya anemia.

Hal ini sejalan dengan penelitian Dzul (2018) bahwa Status ekonomi rendah berisiko terjadinya anemia dua kali dibandingkan dengan ekonomi tinggi pada remaja putri. Hal ini sejalan dengan penelitian Jalambo (2012) yang menyatakan bahwa anemia pada remaja berhubungan dengan kondisi ekonomi. Remaja dengan ekonomi rendah lebih berisiko terjadinya anemia bila dibandingkan dengan ekonomi yang lebih tinggi. Menurut Amaranth (2013) kemiskinan berhubungan langsung dengan kejadian anemia. Kemiskinan akan berpengaruh terhadap daya beli keluarga dan kemampuan dalam memilih makanan. Kondisi ini yang akan berpengaruh terhadap pemenuhan gizi pada remaja. Remaja dengan ekonomi rendah akan berpengaruh terhadap asupan makanan yang kurang berkualitas dan berdampak terhadap anemia (Balarajan, 2011). Menurut Dzul (2018) Status pendapatan orang tua pada remaja putri dapat berdampak pada status gizi. Ekonomi orang tua bukanlah merupakan faktor langsung yang dapat menyebabkan anemia, namun ekonomi orang tua dapat berdampak pada daya beli keluarga. Kemampuan daya beli inilah yang mempengaruhi asupan seharihari remaja putri yang dapat berdampak pada baik dan buruknya status gizi remaja. 
Penelitian yang dilakukan oleh Purbadewi, Ulvie (2013) menemukan bahwa ada hubungan yang bemakna antara pengetahuan tentang anemia dengan kejadian anemia dengan nilai $\mathrm{p}$ sebesar 0,000 . Tingkat pengetahuan pada remaja putri juga dapat mempengaruhi terjadinya anemia, karena pengetahuan dapat mempengaruhi perilaku dan juga pola hidup dan kebiasaan makan. Kurangnya pengetahuan tentang anemia, tanda - tanda, dampak, dan pencegahannya yang akan mengakibatkan remaja mengkonsumsi makanan mengandung zat besi yang sedikit sehingga zat besi pada remaja tidak dapat terpenuhi. Lebih dijelaskan lagi sebagian besar pengetahuan manusia diperoleh melalui mata dan telinga. Pengetahuan atau kognitif merupakan salah satu dominan yang paling penting untuk terbentuknya tindakan seseorang (over behavior). (FKUI,2009 dalam Riyanto 2010).

Hasil penelitian Sirait menunjukkan bahwa terdapat hubungan tingkat konsumsi zat besi dengan kejadian anemia pada remaja putri di SMP Kristen 1 Surakarta. Penelitian ini sejalan dengan penelitian yang dilakukan oleh Kirana (2012) terdapat hubungan yang bermakna antara asupan zat besi dengan kejadian anemia $(p=0,024)$ di SD Inpres Kelurahan Bunaken Kota Manado. Handayani, dkk (2007) menunjukkan bahwa terdapat hubungan asupan zat besi dengan kejadian anemia pada siswi SMU Negeri I Dempet Kabupaten Demak Jawa Tengah $(p=0,025)$. Keterkaitan zat besi dengan kadar hemoglobin bahwa zat besi merupakan komponen utama yeng memegang peranan penting dalam pembentukan darah yaitu mensintesis hemoglobin. Hemoglobin terdiri dari $\mathrm{Fe}$ (zat besi), protoporfirin, dan globin ( $1 / 3$ berat $\mathrm{Hb}$ terdiri dari $\mathrm{Fe})$ (Susiloningtyas, 2004).

\section{Bivariate}

\section{Hubungan Pola Menstruasi Dengan Kejadian Anemia pada Mahasiswi Prodi Sarjana Kebidanan Unissula Semarang}

Berdasarkan hasil analisis didapatkan nilai $p$-value sebesar 0,000 yang artinya terdapat hubungan antara pola menstruasi terhadap kejadian anemia pada Mahasiswi Prodi Sarjana Kebidanan Unissula. Berdasarkan hasil analisis didapatkan bahwa dari 24 responden memiliki pola menstruasi tidak normal didapatkan 22 responden $(91,7)$ mengalami anemia sedangkan sisanya didapatkan bahwa dari 24 responden memiliki pola menstruasi tidak normal didapatkan 2 responden $(8,8 \%)$ tidak mengalami anemia. Penelitian ini sejalan dengan penelitian Amalia (2018) menunjukkan hal yang sama bahwa ditemukan ada hubungan yang bermakna antara pola menstruasi dengan kejadian anemia, yang didasarkan pada hasil uji continuity correction didapatkan nilai $p$ sebesar 0,000 $(<0,05)$. Hasil penelitian Baiq Nuralaily (2015) menunjukkan hal yang sama bahwa terdapat hubungan antara pola menstruasi dengan kejadian anemia pada remaja putri ( $\mathrm{p}$ value $=0,002)$. Hasil penelitian Sirait (2015) manunjukkan hal yang sama yaitu menemukan ada hubungan yang bermakna antara pola menstruasi dengan kejadian anemia.

Menurut Hapzah \& Yulita (2012) Pola menstruasi dapat menyebabkan anemia karena pada saat remaja sedang mengalami menstruasi akan mengeluarkan cairan secara berkala dari vagina selama usia produktif, yang terjadi satu bulan sekali. Menurut Desi (2019) lama menstruasi yang tidak normal akan menyebabkan remaja lebih banyak kehilangan darah saat menstruasi daripada renaja yang memiliki lama menstruasi yang normal. Lamanya proses menstruasi akan mempengaruhi jumlah sel darah merah didalam tubuh, semakin lama proses menstruasi maka semakin banyak darah yang keluar, yang 
mana hal ini dapat menyebabkan masalah anemia pada perempuan.

Menurut Amalia (2018) Semakin pendek siklus menstruasi maka semakin sering frekuensi wanita mengalami menstruasi, hal ini yang dapat menyebabkan perdarahan menstruasi menjadi berlebih. Banyaknya darah yang keluar berperan pada kejadian anemia karena wanita tidak mempunyai persediaan zat besi yang cukup dan absorpsi zat besi kedalam tubuh tidak dapat menggantikan hilangnya zat besi saat menstruasi, dengan demikian adanya anemia pada remaja putri yang mengalami frekuensi menstruasi lebih sering disebabkan jumlah darah yang keluar secara komulatif menjadi lebih banyak. Besarnya zat besi yang hilang pada saat menstruasi tergantung pada jumlah darah yang keluar saat periode menstruasi.

Menurut Gibney (2008) Kehilangan zat besi dengan Perdarahan atau kehilangan darah dapat menyebabkan anemia misalnya pada peristiwa Menstruasi. Pada remaja putri mulai terjadi menarche yang disertai pembuangan sejumlah zat besi (Gibney, 2008). Menstruasi adalah runtuhnya jaringan epitel endometrium akibat pengaruh perubahan siklik keseimbangan hormonal reproduksi wanita. Ciri-ciri menstruasi normal adalah Lama siklus antara 21-35 hari, lama perdarahan 3-7 hari, perdarahan 20-80 cc persiklus, tidak disertai rasa nyeri, darah warna merah segar dan tidak bergumpal (Gibney, 2009). Kehilangan rata-rata darah secara normal pada saat menstruasi adalah sekitar 30 $\mathrm{ml} /$ hari yang sama dengan kebutuhan tambahan 0,5 $\mathrm{mg}$ zat besi per hari. Kehilangan darah setiap hari dihitung dari kandungan zat besi dalam darah yang hilang selama menstruasi selama periode satu bulan. Remaja putri yang kehilangan darah menstruasi lebih dari $30 \mathrm{ml} /$ hari maka remaja putri tersebut tidak akan mampu mempertahankan keseimbangan zat besinya (Gibney, 2009).

\section{SIMPULAN}

Dapat disimpulkan bahwa ada hubungan yang signifikan antara pola menstruasi dengan kejadian anemia Pada Remaja di Prodi Sarjana Kebidanan Unissula Semarang. Diharapkan bagi Remaja untuk selalu konsumsi makanmakanan yang bergizi serta dapat mengkonsumsi tablet tambah darah setiap menstruasi.

\section{DAFTAR PUSTAKA}

Almatsier, S. 2009. Prinsip Dasar Ilmu Gizi. Jakarta : PT Gramedia Pustaka Utama.

Almatsier, S. 2011. Prinsip Dasar Ilmu Gizi. Jakarta : PT. Gramedia Pustaka Utama.

Amalia. 2018. Faktor - Faktor yang Berhubungan dengan Kejadian Anemia Pada Remaja Putri di SMA Muhammadiyah Gubug Kabupaten Grobogan. Undergraduate thesis, Universitas Muhammadiyah Semarang.

Amarnath M, N Lakshmanrao. 2013. Anemia among Adolescent Girls in Tribal Area of Visakhapatnam District in Andhra Pradesh. Indian Journal of Public Health Research \& Development. April-June 2013, 4, 2

Arisman. 2006. Gizi dalam daur Kehidupan Buku Ajar Ilmu Gizi. Buku Kedokteran UGC.Jakarta.

Baiq Nurlaily Utami. 2015. Hubungan Pola Makan Dan Pola Menstruasi Dengan Kejadian Anemia Remaja Putri. Jurnal Keperawatan Soedirman , Volume 10, No.2

Balarajan Y, Ramakrishnan U, Özaltin E, Shankar AH, Subramanian SV. 2011. Anaemia in low-income and middleincome countries. Lancet

Beck, Mary E. 2011. Ilmu Gizi dan Diet: Hubungannya Dengan Penyakit- 
penyakit Untuk Perawat dan Dokter. Yogyakarta: Andi Yogyakarta.

Bobak. 2004. Buku Ajar Keperawatan Maternitas Edisi 4. Jakarta: EGC.

Briawan, D. 2014. Anemia Masalah Gizi Pada Remaja Wanita. Jakarta : EGC.

Cakir M, Mungan I, Karakas T, Girisken L, Okten A .2007. Menstrual pattern and common menstrual disorders amonguniversity students in Turkey. Pediatr Int;49(6):938-42.

Departemen Kesehatan RI. Pedoman Pelayanan Gizi Rumah Sakit. Dirjen Bina Kesehatan Masyarakat. Jakarta, 2003

Dito. 2007. Anemia dan Etiologi Anemia. Bandung : Surya Medika.

Epri, Sugma. 2015. Pengaruh Stres Terhadap Siklus Menstruasi pada Remaja. Artikel Review. Fakultas Kedokteran: Universitas Lampung

Gibney, M.J., et al. 2009. Gizi Kesehatan Masyarakat. Jakarta: EGC, 2009

Guyton A.C, dan Hall,J.E. 2014. Buku Ajar Fisiologi Kedokteran. Edisi 12.Penterjemah: Ermita I, Ibrahim I. Singapura: Elsevier.

Handayani. 2007. Hubungan Status Gizi Dengan Kejadian Anemia Pada Remaja Putri. Program Studi Ilmu Keperawatan Universitas Riau

Hapzah \& Yulita. R. 2012. Hubungan Tingkat Pengetahuan dan Status Gizi Terhadap Kejadian Anemia Remaja Putri. Jurnal kesehatan

Heffner, Linda J \& Schrust DJ. At a glance system reproduksi. Edisi Kedua.

Istiqomah, Dzul. 2018. Pengetahuan, Sosial Ekonomi, Pola Makan, Pola Haid, Status Gizi dan Aktivitas Fisik Dengan Kejadian Anemia Pada Remaja Putri. Jurnal Keperawatan dan Kebidanan Aisyiyah : STIKes Muhammadiyah Pringsewu Lampung

Jalambo MO, Hamad A, Abed Y. 2013. Anemia and risk factors among female secondary studentsin the Gaza
Strip. Journal Public Health: 21:271278

Kemenkes. 2017. Profil Kesehatan Indonesia 2016. Jakarta: Kemenkes; 2017.

Kirana, DP. 2011. Hubungan Asupan Zat Gizi dan Pola Menstruasi Dengan Kejadian Anemia Pada Remaja PutriDi SMA N 2 Semarang. Skripsi. Universitas Diponegoro

Kumala, Desi. 2019. Pola Menstruasi dengan Kejadian Anemia Pada Remaja. Universitas Aisyah Pringsewu Lampung: Wellness And Healthy Magazine

Manuaba. 2008. Ilmu Kebidanan, Penyakit Kandungan, dan KB. Jakarta: EGC.

Notoatmodjo, S. 2007. Promosi Kesehatan dan Ilmu Perilaku. Jakarta: Rineka Cipta.

Prastika D. 2011. Hubungan Lama Menstruasi Terhadap Kadar Hemoglobin Pada Remaja Siswi SMA $N 1$ Wonosari. Karya Tulis Ilmiah Surakarta. Program Studi D IV Kebidanan Fakultas Kedokteran Universitas Sebelas Maret Surakarta.

Prawirohardjo, S. 2018. Ilmu Kebidanan. Jakarta: Yayasan Bina Pustaka Sarwono Prawirohardjo.

Pribakti. 2010. Tips Merawat Organ Intim (Panduan Praktis Kesehatan Reproduksi Wanita). Jakarta.

Purbadewi, L dan Ulvie, Y.N.S. 2013. Hubungan Tingkat Pengetahuan Tentang Anemia dengan Kejadian Anemia pada Ibu Hamil. Jurnal Gizi Universitas

Muhammadiyah Semarang April 2013. Volume 2, Nomor 1.

Riyanto. 2010. Pengetahuan dan Sikap. FKUI 2009

Riset Kesehatan Dasar (Riskesdas). 2007. Pedoman Pewawancara Petugas Pengumpul Data. Jakarta: Badan Litbangkes, Depkes RI. 
Sakti, H., Rachmawati, B., Rahfiludin, M.Z. 2003. Pengaruh Suplementasi Tablet Besi, dan Pe-ndidikan Gizi terhadap Pengetahuan, Sikap, Praktek Tentang Anemi, dan Kadar Hemoglobin (Hb) pada Remaja Putri. Media Medika Indonesiana. 38(1): 24-30

Sarwono. 2011. Psikologi Remaja.Edisi Revisi. Jakart: Rajawali Pers.

Sirait, Aprilliya. 2015. Hubungan Tingkat Konsumsi Zat Besi Dan Pola Menstruasi Dengan Kejadian Anemia Pada Remaja Putri. FK Muhamaddiyah Surakarta

Susiloningtyas, I. 2004. Pemberian zat besi (Fe) dalam Kehamilan. UNISULA Semarang.

Tim Poltekkes Depkes Jakarta I. 2010. Kesehatan remaja problem dan solusinya. Jakarta: Salemba Medika.

Sugiyono. Penelitian Kuantitatif, Kualitatif dan $R \& D$. Bandung: Afabeta, 2011

Widyastuti, Y. Kesehatan Reproduksi. Yogyakarta : Fitramaya, 2009

Wiknjosastro. Ilmu Kebidanan, Yayasan Bina Pustaka Sarwono Prwirohardjo, Jakarta, 2002

Wijayanti, Daru. Fakta Penting Sekitar Reproduksi Wanita. Yogyakarta : Diglosia Printika, 2009

Winkjosastro. 2002. Ilmu Kebidanan. Jakarta: Yayasan Bina Pustaka Sarwono Prawirohardjo.

Wiknjosastro, Hanifa. 2009. Ilmu Kebidanan. Jakarta: Yayasan Bina Pustaka. 